Revista de la red interuniversitaria de estudios sobre las

literaturas rioplatenses contemporáneas en Francia

15 | 2016

Un año. Literatura argentina 1969

\title{
La inteligencia obrera. Notas sobre la experiencia política de los trabajadores en los años '70
}

\section{Roberto Pittaluga}

\section{OpenEdition}

\section{Journals}

Edición electrónica

URL: http://journals.openedition.org/lirico/2845

DOI: $10.4000 /$ lirico.2845

ISSN: 2262-8339

Editor

Réseau interuniversitaire d'étude des littératures contemporaines du Río de la Plata

\section{Referencia electrónica}

Roberto Pittaluga, «La inteligencia obrera. Notas sobre la experiencia política de los trabajadores en los años '70 », Cuadernos LIRICO [En línea], 15 | 2016, Puesto en línea el 03 octubre 2016, consultado el 30 abril 2019. URL : http://journals.openedition.org/lirico/2845; DOI : 10.4000/lirico.2845

Este documento fue generado automáticamente el 30 abril 2019.

\section{cc) $(1) \ominus$}

Cuadernos LIRICO está distribuido bajo una Licencia Creative Commons Atribución-NoComercialSinDerivar 4.0 Internacional. 


\title{
La inteligencia obrera. Notas sobre la experiencia política de los trabajadores en los años'70
}

\author{
Roberto Pittaluga
}

...todo lo que sabemos nosotros lo sacamos de nuestra propia experiencia

Agustín Tosco, 1970

De los acontecimientos de la historia argentina reciente, el Cordobazo ha sido uno de los

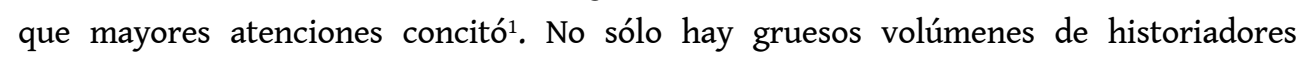
argentinos y extranjeros dedicados a este singular evento, sino que la significación del Cordobazo, lo que esa movilización y ese enfrentamiento, por cierto violento, quería decir, fue objeto de durísimas luchas desde el mismo momento en que las calles de Córdoba eran ocupadas por trabajadores, estudiantes, vecinos². Esta necesidad por otorgarle sentido al acontecimiento Cordobazo es uno de los nudos relevantes de aquella experiencia, de modo que el Cordobazo, además de sacudir la trama política y social argentina, se extendió en sus interpretaciones, las que conviene pensar como parte del acontecimiento, en la medida que en ellas los sujetos se reconocían y elaboraban un campo de sentidos para sus prácticas como también para sus expectativas. Y allí, en la producción de significados para comprender su experiencia, la palabra obrera tuvo un lugar destacado.

\section{Narrar(se)}

2 El propio Agustín Tosco, una de las figuras emblemáticas de aquellas jornadas, sintió la necesidad de significar la gesta cordobesa, de convertir en palabras, frases, texto, aquello que los cordobeses habían expresado con movilizaciones masivas, barricadas, enfrentamientos con la policía y el ejército, quema de locales de las grandes empresas, toma de las calles, los barrios, etc. En su «Testimonio del Cordobazo»-publicado en junio de 1970, a un año de lo sucedido- salía al cruce de las versiones que enfatizaban el 
carácter espontáneo del Cordobazo, donde espontáneo quería decir episódico y a la vez fuera del control de las capacidades humanas, como una suerte de terremoto social, un movimiento involuntario. «No hay espontaneísmo. Ni improvisación», afirmaba el lucifuercista, pues esas lecturas no daban cuenta del papel de los promotores, del trabajo preparativo, de la experiencia y del saber de los trabajadores (Tosco 1988: 54).

Ese énfasis en la preparación, en el carácter no espontáneo de la movilización se repite en muchos relatos de los protagonistas. Jorge Canelles, comunista y activista de la construcción de larga militancia, sostenía que

el Cordobazo fue organizado, se determinó por dónde tenían que marchar las columnas y se llamó a concurrir con todos los elementos contundentes que se pudieran. Ahora, para tener una idea, SMATA cumplió la cosa, hizo más de tres mil molotovs en el campo de deportes. SMATA, ¿no? Aparte de las otras organizaciones. O sea, no se fue desguarnecido (2001). ${ }^{3}$

4 En el mismo sentido, pero avanzando en una lectura de los motivos de las versiones espontaneístas, Juan Carlos Cena apunta que «algunos personajes opinan desde el borde de la historia [...] con una profunda vocación por la distorsión, el ocultamiento, y la manipulación de lo ocultado», cuando siguen manifestando «que los hechos acontecidos en Córdoba fueron espontaneísmo puro», o cuando desplazan el protagonismo desde la clase obrera a «los estudiantes, la clase media, el botellero, las amas de casa» (1998: 272). Con su agudeza habitual, Cena entiende esa minusvaloración del rol de la clase obrera en la insurrección del 69 como una interpretación que, sottovoce, quita a los trabajadores «el derecho a opinar sobre sí mismos y sobre las grandes cuestiones nacionales», mientras que «una concepción» bien distinta era la «reinante por esos tiempos» de levantamientos y puebladas (1998: 272). Todos los intentos por reemplazar el protagonismo de los trabajadores por el de los estudiantes, además de provenir de un pensamiento reaccionario son incapaces de percibir que «hacía mucho» que estudiantes y obreros «andaban codeándose por estos parajes», ya sea porque muchos estudiantes trabajaban o porque muchos trabajadores estudiaban, desdibujando de este modo dichos perfiles identitarios como elementos fijos y dando lugar a «relaciones sociales nuevas» (Cena: 272).

5 Pero a estas coincidencias interpretativas se suma otra que de algún modo las matiza, y hasta parece contradecirlas. Es cuando se reconoce que a partir de cierto momento -se nombra generalmente la muerte de Mena, trabajador de SMATA- el acontecimiento toma una magnitud no prevista por los organizadores del paro y la demostración callejera. En palabras de Canelles: «es cierto que cuando casi simultáneamente nos enteramos de la muerte de Mena, que lo matan a Mena, ya la cosa se hizo incontrolable» (Canelles 2001) ${ }^{4}$. Agustín Tosco apuntaba la causa: «Nadie controla la situación. Es el Pueblo» (1988: 54). El propio Juan Carlos Cena pone en boca de sus compañeros ferroviarios la dimensión imprevisible del acontecimiento: «Fue un contagio este quilombazón. Se esperaba pero no tanto. El barrio salió a la calle. Los viejos curcunchos, jugadores de bochas y campeones del juego al sapo, le dieron a la piedra. Doblaban la cintura acarreando piedras. Los pendejos meta hondazos» (1998: 287) 5 .

6 Oscilaciones del relato obrero. La clase se prepara, pero el acontecimiento que produce supera la situación. ¿Espontaneísmo? El término molesta porque pareciera eliminar la continuidad de la lucha, los pequeños y grandes combates que precedieron a la insurrección de mayo, pero sobre todo porque parece borrar la agencialidad proletaria. Pero eso que se nombra como espontaneísmo no necesariamente es contradictorio con la 
preparación, la labor diaria, la lucha previa, los antecedentes. Hay continuidad y discontinuidad. La narración de Cena sutura las discontinuidades que a la vez expone al inscribirlas en el relato; dialéctica del idem y del ipse que ponga al sujeto como uno y a la vez ex-ponga sus transformaciones: «El Cordobazo fue un catalizador. Lo que fue o existió, en una situación normal, apacible para algunos, ese día que era 29, de pronto estalló en forma espectacular y todo se trastocó» (1998: 296-97).

Cotidianeidad trastocada, afirma el ferroviario. El trastocamiento es otro nombre de la emancipación, pues en esas jornadas, la norma alterada -todo estallado y trastocado, todo explotado- era la expresión del afloramiento de lo que está en carena, de esa ruptura primordial de la política moderna alojada en la no coincidencia entre el Pueblo integrado del cuerpo político que incluye a todos y es titular de la soberanía, y el pueblo bajo, el menu peuple, les miserables, «multiplicidad fragmentaria de cuerpos menesterosos y excluidos», «la clase que, de hecho sino no de derecho, está excluida de la política» (Agamben 2001: 27-31).

8 Continuidad. La palabra y la praxis obrera que relatan los protagonistas como antecedentes del Cordobazo es el gesto político que el pueblo de Córdoba retoma y al hacerlo instituye una escena política nueva ${ }^{6}$. Esa praxis del clasismo es un acto de vanguardia en tanto gesto -como práctica- que puede ser retomado por cualquiera sin tener pretensiones impositivas.

Discontinuidad. La rebelión puede ser punto de inflexión en las diversas narrativas porque, como señalara Tosco, el pueblo se evade del control («Nadie controla la situación. Es el Pueblo»), se desliza de las subjetividades existentes («lo que fue o existió», «la normalidad, apacible para algunos» como dice Cena) por una subjetivación política que lo constituye como agente; explicita la lucha de clases que anida en la política moderna. El jugador de bochas, el pendejo, el vecino, cualquiera -diría Rancière- se convierten en lanzadores de piedras, honderos, activistas antidictatoriales, levantadores de barricadas, que alojan «como hijos» a los estudiantes perseguidos por la patrulla militar?

10 Lo que pareciera no haber existido antes, lo espontáneo, es la aparición de la clase o el pueblo como acontecimiento no previsto en los roles heterónomos de la construcción social. Esa irrupción -o «explosión» como dicen varios protagonistas- es la expansión de una política antecedente -la de la militancia clasista- más allá incluso de la perduración del evento. Pero esa aparición tiene su fundamento en la escisión que constituye el cuerpo político moderno; se trata de una escisión originaria -es decir, arcóntica- que la lucha de clases nombra y expresa. Por eso, como señala Agamben, a pesar de que la modernidad hegemónica se caracteriza por el intento de suprimir esa escisión -ya sea de modo reactivo o progresivo- no se puede, agreguemos, resolver el problema del tiempo (continuidad, corte, detención) de una subjetivación y una práctica política en el solo plano de la continuidad fenoménica, en la semejanza de lo emergente (antecedente/ consecuente). Lo que dura/perdura una acción depende, también, de su conversión en experiencia; de allí la crucial importancia que estos trabajadores le dieron a la interpretación, a la narración del Cordobazo; de allí su atención al relato micropolítico de los protagonismos populares junto a las caracterizaciones y perspectivas generales que ensayan, en un movimiento de mutua iluminación por el pasaje entre perspectivas macro y micro. Interpretar y narrar las insurrecciones como las del 69 ha sido una dimensión inherente a las mismas acciones y prácticas que se sucedieron en su nombre. Pues como dice Alain Badiou, «lo que subsistirá del acontecimiento es lo que habrá sido decidido a propósito suyo y que es, finalmente, su nombre» (Badiou 1998). 

1998: 297). Interpretar el Cordobazo no es sino un aspecto de un relato de la aparición del pueblo, de la historia de la clase proletaria, de su existencia. ¿Cómo relatan estos trabajadores su propio recorrido desde la normalidad serializada al protagonismo sindical?

«La esencia de esto es poder transmitir esta historia que es la historia de la clase trabajadora pero es la historia del pueblo argentino», enfatiza Taurino Rufino Atencio al brindar su testimonio para Memoria Abierta y el Archivo de la Comisión Provincial de la Memoria (Córdoba) en 2009. La historia de la clase obrera es la historia del pueblo; la construcción semántica relaciona el hito histórico con la subjetivación política:

aparece acá, [se refiere a los años que rondan el Cordobazo] en todo esto, un nuevo actor que no es el clásico agente diríamos [...] el nuevo agente de la historia aparece acá, que es la clase trabajadora. Para atrás nosotros vemos que existen generales, doctores, funcionarios de gobierno, sacerdotes de alta alcurnia, y aquí aparece este nuevo sujeto social... que no solamente aparece en escena sino que [lo hace] con el concepto de la liberación, con el concepto de que nosotros tenemos que trabajar para eliminar la injusticia que es lo que hace infeliz a una persona (Atencio 2009).

Por un lado, la intercambiabilidad entre clase y pueblo da cuenta de la separación entre pueblo y Pueblo, en el sentido que Marx da al proletariado como aquella parte de la sociedad que no es una parte de la sociedad, y por ello puede pronunciar la palabra emancipatoria, el «concepto de la liberación» como señala Atencio, exponiendo una conceptualización de la clase como aquella subjetivación política antagonista a ese orden social que «hace infeliz» a las personas. Al retomar la idea de felicidad se produce también un corte, una discontinuidad con la idea de progreso, en la medida que no se trata de lograr una vida mejor (que puede suponer una corrección de los aspectos negativos de un curso histórico humano juzgado generalmente como positivo) sino de una transformación de base de las relaciones de injusticia del régimen actual. Esa injusticia aparece una y otra vez cuando estos trabajadores tienen que dar cuenta de su condición en la sociedad. A veces lo hacen colocando en segundo plano los motivos económicos de la insurrección (Cena 2006), otras explicando los mecanismos y las consecuencias de la explotación ${ }^{8}$.

Hay un hiato en los relatos sobre la militancia cuando se trata del pasaje al activismo clasista. Las narraciones tienen que dar cuenta de ese momento de corte subjetivo, una brecha que se percibe en el modo del relato de muchos de los trabajadores cuando rememoran esa experiencia, que es generalmente narrado como si las decisiones no fueran propias, como si los aconteceres les sucedieran (Masera 2009). Formas del relato que buscan dar cuenta de ese cambio, ese desplazamiento del mero obrero al activistaobrero, de la masa serial a la clase, casi como si viniera de fuera de los sujetos. Instancia de ipseidad, para nombrar «ese nuevo actor» del que hablara Atencio; instancia de dessubjetivación que implica el abandono del actante, e instancia de subjetivación, siempre en riesgo de convertirse en otra sustancialidad que los aferre a nuevos roles sociales (Rancière 1996 y 2011; Butler 2014). El riesgo es inherente a la experiencia, a la cual todos los trabajadores finalmente asignan sus saberes -como en el epígrafe de Tosco que abre este escrito. Y a la experiencia es también inherente la noción de recorrido. El riesgo de un atravesamiento de las figuras sociales para producir una inédita.

Cuadernos LIRICO, 15 | 2016 


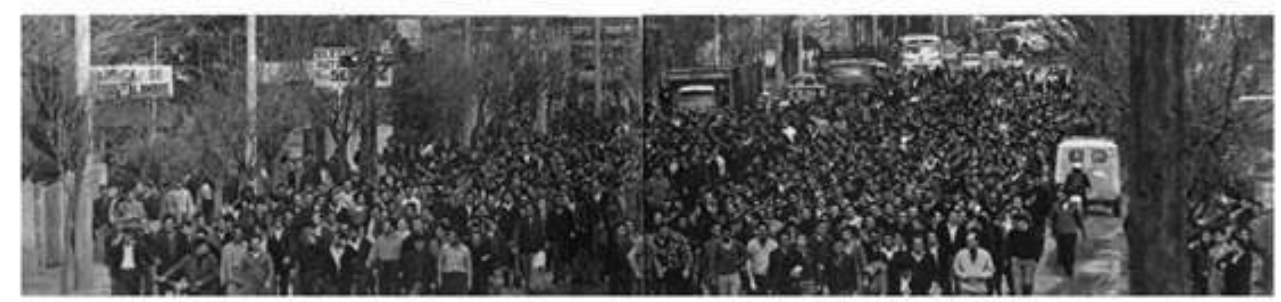

Foto a doble página en Siete Días Ilustrados. Edición Extra, 3 de junio de 1969

16 La foto de la revista Siete Días nos muestra una columna de trabajadores marchando hacia el centro de la ciudad, un sujeto que, significativamente, no precisa identificarse -no hay pancartas, carteles alusivos, nombres. «Decía la radio, que esa columna marchaba sin portar carteles ni banderas», comenta Cena mientras refiere su llegada a Córdoba capital ese mismo 29 de mayo (1998: 280). Y Canelles, diferenciando el Cordobazo del Viborazo, apunta que en el primero «vamos todos unidos» contra la dictadura, sin que hubiera «pancartas ni consignas partidarias de ningún tipo» (Canelles 2001) 9 .

Bien podría interpretarse esa ausencia de banderas en la permanencia de una identidad popular. O también que el pueblo no se presenta más que ante sí mismo y por lo tanto no precisa de marcas de identidad para que Otro lo reconozca; no se muestra, demuestra. Interpretaciones plausibles, no sólo de la fotografía sino también de muchos de los testimonios epocales y de los rememorativos. «Todos unidos» decía Canelles, unidos como uno. ¿Pero se trata, efectivamente, de una unidad identitaria? ¿Y de qué identidad estaríamos, entonces, hablando? ¿En qué situación el pueblo puede ser adjetivado identitariamente sin producir el deslizamiento hacia el otro polo y convertirlo en Pueblo? ¿La clase obrera es una unidad identitaria o una unidad plural?

En un cartel escrito por los trabajadores de SiTraC-SiTraM durante una de las tomas del establecimiento, puede leerse:

Viva la clase 'obrera' de FIAT. ${ }^{10}$

¿Qué significa que allí, en lo que se piensa como el corazón del clasismo, la condición obrera sea puesta entre comillas y a la vez (aparentemente) subrayada de modo intermitente? Quizás un reforzamiento de la identidad obrera, de ese clasismo obrerista del que fueron muchas veces tildados -y que evidentemente fue parte de esa experiencia. Pero también podemos leer el entrecomillado como una duda, una sospecha. Doble sospecha ex-puesta por estos trabajadores. Que su condición obrera no es ya (o no debería ser) la del trabajador industrial como tal. Que el obrerismo no puede (o no debería) ser nunca una identificación estable, una identidad, sino estar siempre pasando, estar entre el abismo que significa cualquier des-subjetivación, cualquier abandono del lugar y la identidad social asignados y esa subjetivación emergente, crítica y a la vez frágil, en peligro de ser nuevamente identidad. Que, como el subrayado de la pancarta, se trata de una identificación intermitente.

Si nos detenemos a mirar muchas de las fotos e imágenes fílmicas de las jornadas del Cordobazo, y si extendemos esa mirada hacia otras insurrecciones, puebladas, de esos años, no nos hallamos frente a un sujeto socialmente bien determinado ${ }^{11}$. A pesar de ello, la mayoría de las lecturas de la consigna «obreros y estudiantes» la interpretan como la unión de dos sectores de la sociedad desencontrados en los años del primer peronismo. Otra sería la lectura si se pusiera el acento no tanto en «obreros» y «estudiantes» sino en la «y». Porque la conjunción da cuenta más que de la unión de dos sectores, de la hibridez 
de la subjetivación política que está en el entre, en el desplazamiento que hace de ese sujeto uno inadscribible al rol social (obrero, estudiante) ${ }^{12}$. El sujeto de la revuelta, de la emancipación, es un híbrido, es un sujeto que pasa del lugar social a uno político que él mismo se inventa, es un sujeto nómade -característica de todos los procesos formativos de la clase obrera ${ }^{13}$.

¿Pero qué es lo que evitaría, eventualmente, la nueva sustancialización de una identidad obrera y con ella la nueva sujeción a una condición o a un lugar social desde entonces indeliberado?

\section{Democracia obrera: las políticas de lo común}

En cada comida que compartimos, se invita a la libertad. La silla siempre está vacía, pero su lugar está asignado

René Char

La tarea de narrarse es también la de poner en el combate político su propia estrategia, a través de una discursividad que sea expresiva de la praxis obrera y a la vez la module. Un concepto aparece como elemento medular del discurso de la vanguardia obrera de los 60/70: la democracia de bases, la democracia sindical. Si bien no pocas veces es invocada en contextos políticos restrictivos (Tosco 1988: 195) o frente a la «burocracia sindical», sería minimizar el asunto pensar que esa demanda de lo democrático tiene meramente esos sentidos. El discurso democrático de base, más profundamente, busca expresar esa modalidad de existencia, de aparición de la clase. Nuevamente es Tosco quien habla:

Ya sea en el terreno institucional, en el de la resistencia e incluso en la clandestinidad, no hay otra relación posible que la democracia de bases. Es decir, el contacto directo entre los trabajadores y sus representantes o dirigentes. La concienciación a nivel de bases. La reciprocidad del intercambio de opiniones. Las asambleas generales, las de sectores, las de unidades de trabajo. Claro que hay diferencias para una situación institucional, de resistencia o de clandestinidad. Pero en definitiva en el terreno del sindicalismo nada es válido sin la democracia de bases y la consecuente reciprocidad entre las bases y las direcciones (1988: 15). ${ }^{14}$

En los relatos obreros existe un notable esfuerzo argumental para dar cuenta de esa praxis, distinta de cualquier idealización de un basismo a ultranza que correría el riesgo de una disolución completa de la clase. Al solidarizare con la lucha de los trabajadores de Villa Constitución, Tosco intentaba transmitir su propia experiencia en estos términos:

Creemos en la relación dialéctica positiva de base-dirección y dirección-base. Las bases sin conducción pasan por lo general al espontaneísmo y a la disgregación tornando inútiles los esfuerzos colectivos y facilitando la represión. Las conducciones sin base pasan a ser pequeños grupos sin ecos y sin capacidad de movilización concluyendo por lo general en múltiples divisiones (1988: 396-97).

Esa «relación dialéctica» se descubre en las entrevistas a los activistas de SiTraC-SiTraM realizadas por los editores de Pasado y Presente en 1971, al ser presentada como una diferencia cualitativa con otras políticas existentes en el mundo de los trabajadores (y más allá). Ante las preguntas del entrevistador, los activistas del sindicato clasista explican el funcionamiento asambleario y los modos de delegación, enfatizando el carácter medular del mecanismo democrático no sólo como forma de toma de decisiones sino, más densamente, como forma de la clase trabajadora, esto es, como la modalidad propia de su aparición, de su existencia (Schmucler et. al. 2009: 211). Si puede decirse que la clase está siempre en formación -como sostiene Rancière- esa forma de acción de la democracia de bases es un aspecto constituyente y constitutivo de la misma, el modo de 
una subjetivación política alternativa, y potencialmente emancipatoria; de allí que Tosco, aun en momentos en que auguraba un futuro próximo negativo no dejaba de señalar, en 1975, que resultaba «imprescindible mantener a toda costa el funcionamiento legal, semilegal o clandestino del Comité de Lucha y del Cuerpo General de Delegados en una relación abierta y democrática con las bases» (1988: 397). Impulsar la rebeldía y sumar trabajadores a las estructuras de resistencia no implicaba, para el cordobés, apartarse de un funcionamiento abierto a las bases (1988: 397); la clandestinidad no significaba, de este modo, un alejamiento hacia instancias separadas y tabicadas sino la adopción de mecanismos de toma de decisiones adaptados a la lucha ilegal pero con y en las bases.

Esta forma de la clase -que, repitámoslo, es una política, una emergencia subjetivaalternativiza las estructuras verticalistas del movimiento obrero consolidado, pero también colisionaba, a veces más abiertamente que otras, con las políticas de los partidos de la izquierda, armada o no armada, o con la izquierda peronista ${ }^{15}$. De modo que en no pocas ocasiones los mismos trabajadores que recrean cada vez a la clase obrera combativa en la reunión democrática y argumentan plenamente convencidos por dicha práctica política, se exteriorizan respecto de la misma cuando hablan desde posiciones de identidad partidaria, exponiendo una escisión entre democracia obrera y lo que piensan es «la política» ${ }^{16}$. Se revela así una divergencia política de envergadura, una bifurcación de las políticas al interior mismo de las subjetividades obreras, una configuración polar y en tensión de la vanguardia obrera ${ }^{17}$.

Porque si la democracia de bases mina las prerrogativas de la representación -de ciertas modalidades y temporalidades de la representación- más profundamente, esa forma que es la reunión asamblearia y el mandato, destituye las políticas identitarias y a la vez no alcanza nunca a configurarse como otra práctica de la identidad, pues el enunciado, «nosotros, los trabajadores» o «nosotros, el pueblo» es siempre un enunciado incompleto y plural (Butler 2014) ${ }^{18}$. Por eso Carlos Masera decía que «[n]osotros éramos independientes de los partidos, pero éramos políticos. Queríamos participar y entender la política, no nos queríamos inhibir de ella. La intención de plantear el clasismo era asumir que éramos la clase dominada y que queríamos defender los intereses de esa clase» (s/f. [c. 1998]). En una reunión con antiguos militantes sindicales, Masera volvía sobre este asunto del clasismo: «el sindicato se hizo clasista para no ser partidario» (en Malecki 2014: 52$)^{19}$. Bien puede inferirse que la clase, o una política de clase, aparece en este recuerdo como alternativa no sólo frente al poder estatal y patronal sino también frente a las representaciones partidarias, frente a cualquier forma de identidad partidaria de los trabajadores ${ }^{20}$. Alternativa, no necesariamente oposición. En el seno del clasismo convivían esas identidades siempre que se sometieran a la praxis unitaria (y a la vez plural) de la democracia obrera.

La inteligencia obrera no entiende que la democracia de bases tuviera por función, meramente, la de transparentar la gestión en el movimiento obrero, ni que su rol fuera participar como subalterna en las esferas del poder burgués y capitalista, sino «impulsar las transformaciones revolucionarias». Pero ese papel, advertía Tosco,

lo estamos jugando fundamentalmente desde las organizaciones de base y debemos insistir sobre ello. Porque es desde allí donde se genera únicamente el sindicalismo auténtico. Sólo haciéndonos eco de los reclamos que parten del propio pueblo es como podremos encontrar soluciones populares. Toda concepción de élites, en uno y otro sentido, a favor del sistema o supuestamente contra él, termina sirviendo a su consolidación (1988: 205-06). 

únicamente en las organizaciones de base, es porque hay en ello un aspecto propiamente político insustituible por cualquier lógica de las élites, aun de aquellas que «supuestamente» enfrentan el poder capitalista. La insistencia de estos dirigentes es digna de la mayor atención. Si para el lucifuercista cordobés «estas reuniones de base son de tanta trascendencia», la razón principal no habría que buscarla tanto en sus repercusiones (que de todos modos no minimiza) sino en «su práctica constante», en «su reiteración en organizar desde abajo», ampliando e intensificando las reivindicaciones populares (1988: 206). Es que la reunión misma de los trabajadores, ese agrupamiento horizontal e igualitario, donde todos participan y tienen el mismo derecho a ejercer la palabra, como instancia de re-unión -de una unidad distinta a la que produce la disposición seriada y homogeneizante de la clase por el capital, o la uniformización de lo uno bajo el paraguas identitario- es la emergencia de una política performativa de un nosotros desplazado del rol de trabajadores que asigna el orden social. Incluso antes de la enunciación de sus demandas hay una enunciación implícita en esa reunión democrática que coloca en la escena una política contradictora y subversiva de jerarquías y roles sociales, como también de identidades preconcebidas. Es la reunión sin banderas de las columnas obreras del Cordobazo. Sus «repercusiones», podríamos decir, no equivalen a la difusión mediática, sino a lo que esa práctica política implica como alternativización efectiva de las políticas de los sujetados. Por eso, esta intelectualidad obrera no puede sustancializar la misma existencia de la clase sino que la percibe en su formación reiterada, en su forma: «Conceptuamos al movimiento obrero como una práctica eminentemente democrática» (Tosco 1988: 246). El movimiento es una práctica, la clase es una práctica, es comunismo como acontecimiento, como acontecer de una potencia que bajo el capitalismo se encuentra invisibilizada y que se expone en la reunión de ese nosotros capaz de articular en la unidad la multiplicidad de ideas, identidades, saberes, experiencias, trabajando como factor de lo común ${ }^{21}$.

El carácter medular de la práctica democrática para una política emancipatoria, Tosco lo percibía con claridad, y es por ello que convocaba a defenderla allí donde existiera y a promoverla donde faltara, en condiciones legales o clandestinas, dependiendo de la situación (1988: 354). Esa práctica democrática que es la clase evita las sustancializaciones identitarias, es una experiencia que alimenta, al narrar(se), la formación de la clase, y desbarata los dispositivos fabriles que paralizan la imaginación del obrero haciendo de su trabajo algo reactivo a la experiencia ${ }^{22}$. Esa práctica democrática es la posibilidad de la unidad y la pluralidad, entendidas como igualdad sin mecanismos homogeneizadores. Es el lugar de la palabra obrera como palabra antagonista.

\section{BIBLIOGRAFÍA}

\section{Archivos}

Archivo Oral de Memoria Abierta 
Colección Lista Marrón, UOM, Villa Constitución, Memoria Abierta.

Archivo SiTraC (online): http://www.archivositrac.org.ar/el-archivo/

Fuentes primarias

Impresas

CEDIP (Centro de Estudios y Difusión Peronista) (1972), «El mendocinazo. Crónica, análisis y relatos», Cuadernos de antropología del 3er mundo, Buenos Aires, año 1, nº 2, julio.

Cena, Juan Carlos (1998), El guardapalabras. Memorias de un ferroviario. Prólogo de Osvaldo Bayer, Buenos Aires, La Rosa Blindada.

Córdoba, Aníbal (1971), El «Cordobazo». Apuntes de un combatiente, [Córdoba], Anteo.

Díaz, Rubén (1999), Esos claroscuros del alma. Los obreros navales en la década del '70, La Plata, El sueñero.

Masera, Carlos (s/f. [c. 1998]), Entrevista de María Eugenia Eltkin, en Política, sociedad y cultura en Los ' $70, \mathrm{n}^{\circ} 8$.

Martínez, Tomás Eloy (1973), La pasión según Trelew, Buenos Aires, Granica.

Paulón, Victorio (2012), Una larga huelga. Historias de metalúrgicos, Buenos Aires, Desde el subte.

Schmucler, Héctor; Malecki, J. Sebastián y Gordillo, Mónica (2009), El obrerismo de Pasado y

Presente. Documentos para un dossier (no publicado) sobre SiTraC-SiTraM, La Plata, Ediciones Al

Margen.

Tejerina, Hernán; Roitman, Susana; Cabral, Ximena y Olivera, Emilia (2010), El torno y la molotov. Relatos e imágenes de la Córdoba obrera 60-70, Córdoba, Universitas-Jorge Sarmiento Editor.

Tosco, Agustín (1988), Escritos y discursos, Buenos Aires, Contrapunto.

Tosco, Agustín (2009), Textos reunidos. 1953-1972, Córdoba, UNC.

Tosco, Agustín (2011), Textos reunidos II. 1972-1975, Córdoba, UNC.

Tosco, Agustín (1973), «Reportaje Exclusivo», en Ya, 13 de agosto.

\section{Audiovisuales}

Memoria Abierta, Testimonio de Américo Aspitia, Córdoba, 2009.

Memoria Abierta, Testimonio de Carlos Masera, Córdoba, 2009.

Memoria Abierta, Testimonio de Jorge Canelles, Buenos Aires, 2001.

Memoria Abierta, Testimonio de Juan Carlos Cena, Buenos Aires, 2006.

Memoria Abierta, Testimonio de Oscar Álvarez, Córdoba, 2008.

Memoria Abierta, Testimonio de Santos Torres, Córdoba, 2009.

Memoria Abierta, Testimonio de Taurino Rufino Atencio, Córdoba, 2009.

Memoria Abierta, Testimonio de Zenón Sánchez, Villa Constitución, Santa Fe, 2007.

\section{Fuentes secundarias}

Agamben, Giorgio (2001), Medios sin fin: notas sobre la política, Valencia, Pre-Textos.

Badiou, Alain (1998), «Conferencia sobre El ser y el acontecimiento y el Manifiesto por la filosofía», en Revista Acontecimiento, VIII, 15, pp. 21-49. 
Bohoslavsky, Ernesto y Yappert, Susana (2012), Elegantes y rebeldes. El Rocazo, General Roca, Fondo Editorial Municipal.

Butler, Judith (2014), «Nosotros, el pueblo. Apuntes sobre la libertad de reunión», en AA.VV., ¿Qué es un pueblo?, Buenos Aires, Eterna Cadencia, pp. 47-67.

Cena, Juan Carlos (2000), El Cordobazo, una rebelión popular, Buenos Aires, La Rosa Blindada.

Crenzel, Emilio (1991), El Tucumanazo (1969-1974), Buenos Aires, Centro Editor de América Latina.

Duval, Natalia (1988), Los sindicatos clasistas: SiTraC (1970-1971), Buenos Aires, Centro Editor de América Latina.

Funes, Susana (1984), «Agustín Tosco. Dirigente revolucionario», Hechos y protagonistas de las luchas obreras argentinas, $\mathrm{n}^{\circ} 6$, agosto.

Gordillo, Mónica (2009), «Pasado y presente de la autonomía obrera», en Schmucler, Héctor; Malecki, J. Sebastián y Gordillo, Mónica (2009), El obrerismo de Pasado y Presente. Documentos para un dossier (no publicado) sobre SiTraC-SiTraM, La Plata, Ediciones Al Margen, pp. 19-30.

Licht, Silvia (2004), Agustín Tosco y Susana Funes, historia de una pasión militante. Acciones y resistencias del movimiento obrero, Buenos Aires, Biblos.

Pittaluga, Roberto (2016), «La inteligencia obrera. Notas sobre la experiencia política de los trabajadores en los años '70», en Barletta, Ana; Cernadas, Jorge y Lenci, Laura, Futuros en pugna: actores, dinámicas y sentidos durante el tercer gobierno peronista (1973 - 1976), La Plata, UNLP, en prensa.

Ramírez, Ana Julia (2001), «Las puebladas en la Argentina de los '70. El Caso de General Roca, julio de 1972», Ponencia presentada en LASA 2001, Washington, septiembre.

Ramírez, Ana Julia (2003), The People's Collective Politics. Mobilization, Radicalization, and Political Change in Argentina (1966-1973), mimeo.

Ramírez, Ana Julia (2007), «Las mediaciones locales de la protesta. El caso del Trelewazo (octubre de 1972)», en Sociohistórica, № 19 /20, Buenos Aires, Prometeo.

Ramírez, Ana Julia y Viguera, Aníbal (2006), «La protestation sociale dans les trois dernières décennies du XXe. Siècle», en Matériaux pour l' histoire de notre temps, Bibliothèque de Documentation Internationale Contemporaine, Université de Nanterre, Francia, № 81, eneromarzo.

Rancière, Jacques (1996), El desacuerdo. Política y filosofía, Buenos Aires, Nueva Visión.

Rancière, Jacques (2011), El tiempo de la igualdad. Diálogos sobre política y estética, Barcelona, Herder.

\section{NOTAS}

1. El presente artículo es una versión parcial de un trabajo que forma parte del libro colectivo Futuros en pugna: actores, dinámicas y sentidos durante el tercer gobierno peronista (1973 - 1976), de próxima publicación por la Universidad Nacional de La Plata.

2. No es el propósito de este artículo elaborar una interpretación del Cordobazo ni esbozar una historia de las luchas y acciones de las vanguardias obreras de los años 60 y 70. Lo que aquí se propone es indagar en las dimensiones políticas de esas experiencias a partir de los testimonios, actuales y epocales, de algunos protagonistas.

3. La reiteración, con tono de asombro, de lo hecho por SMATA quiere enfatizar el grado de preparación del evento exponiendo el alcance que tuviera en el ala burocrática de los 
convocantes. Véanse, en el mismo sentido Oscar Álvarez (2008) y Córdoba, Aníbal (1971). En adelante, los testimonios del archivo oral de Memoria Abierta se citarán respetando los criterios de citado de las obras impresas, es decir, con el apellido del testimoniante y año de realización de la entrevista; la referencia completa figura en la bibliografía.

4. Taurino Atencio, ex activista de Luz y Fuerza de Córdoba, luego de afirmar que «el Cordobazo fue pensado y programado para ser una gran manifestación popular que generara el mayor quilombo posible» advierte que «después los hechos resultaron superiores a lo previsto» y que con el asesinato de Mena «las cosas entonces tomaron una dimensión inaudita [...] eso fue como echar nafta al fuego» (en Tejerina et. al. 2010: 50-52); más adelante, en la misma entrevista y luego de ver fotos sobre las jornadas del 29 y 30 de mayo de 1969, afirma: «No esperábamos semejante quilombo» (54).

5. Véase también cuando relata cómo salieron los vecinos y el rol que en ello le cupo a la represión, en pp. 288-89. Muchísimos testimonios de otras insurrecciones de esos años reiteran esta descripción de la sorpresiva participación masiva de los vecinos de los barrios. Véanse, por ejemplo, lo expresado por un militante obrero del azúcar respecto del Tucumanazo en Crenzel (1997:163-64); el testimonio de Zenón Sánchez sobre el Rosariazo en Memoria Abierta 2007; el relato de Tomás Eloy Martínez sobre el Trelewazo (Martínez 1973) o el de Victorio Paulón sobre la experiencia de Villa Constitución (Paulón 2012: esp. 72 y ss.).

6. «Algo pasó ese día en Córdoba [...] los vecinos de todos los barrios salieron y prendieron fuego a lo que tenían a mano. Como si un diablo volador los contagiara con los infiernillos, infiernitos, infiernos, aquí y más allá. Como si los dioses del fuego descargaran sobre este territorio un braserío infernal, inapagable, que el aire se cansó de transportar de un lado a otro», en Cena (1998: 289).

7. Véase el relato de Cena (1998: 293).

8. Véanse Santos Torres (2009); Américo Aspitia (2009); Carlos Masera (2009); Domingo Bizzi (en Tejerina et. al., 2010: 83); Rubén Díaz (1999: 40-41); y el Boletín no 1 y el no 2 de SiTraC, de 1971, en Duval (1988: 80-84).

9. No es que faltaran todo tipo de carteles; había algunas pancartas y banderas de sindicatos, como también otras que exponían las demandas; pero eran escasas.

10. El cartel aparece en un fílmico del Canal 10 de Córdoba.

11. Al respecto, véanse los trabajos de Ana Julia Ramírez (2001; 2003; 2007); Ana Julia Ramírez y Aníbal Viguera (2006), Emilio Crenzel (1991), Ernesto Bohoslavsky (2012), Tomás Eloy Martínez (1973); CEDIP (1972) entre otros.

12. Remitimos al lector a la cita de Cena antes mencionada, en relación a que muchos estudiantes eran trabajadores, y viceversa, lo que torna inestables sus «identidades sociales».

13. Testimonios que dan cuenta que el conjunto «pueblo insurrecto» es más que la sumatoria de los conjuntos definidios por «identidades» sociales (obreros, estudiantes, empleados, profesionales, etc.), pueden consultarte en todas las fuentes primarias que se citan al final de este trabajo y en las construcciones historiográficas referidas en la nota 11. María Cecilia Cangiano percibe esta problemática en su trabajo sobre la experiencia de Villa Constitución en los 70.

14. «[L]as asambleas de fábrica como expresión máxima de la democracia obrera» puede leerse en uno de los tantos documentos/hojas volante impresos por el clasismo de Villa Constitución; ver Movimiento Metalúrgico 7 de septiembre Lista Marrón, «A los trabajadores metalúrgicos», s/f. [1974].

15. No es posible, por razones de espacio, desarrollar estas dos cuestiones aquí. Un análisis más extenso en Pittaluga (2016).

16. Véase al respecto el diálogo que varios activistas de SiTraC-SiTraM, militantes además de alguna de las tendencias políticas de la izquierda partidaria, sostienen con la revista Pasado y Presente (Schmucler et. al 2009). 
17. Una polaridad equivalente se manifiesta en ciertas ambivalencias de las reflexiones de Tosco a propósito de las posiciones de SiTraC-SiTraM, del plenario de sindicatos clasistas, de las críticas de Atilio López, de las posiciones de los intelectuales y los partidos, etc., en las cartas que envía a Susana Funes desde la cárcel de Devoto entre mayo y septiembre de 1971; ver Licht (2004: 107-111).

18. Una defensa de la política revolucionaria en clave identitaria (en este caso, peronista) frente al desafío que implica el clasismo puede cotejarse en Corriente Estudiantil Nacional PopularCENaP/UNE, «El CENaP ante el programa SITRAC-SITRAM», Antropología 3er mundo, no 8, sept.-oct. 1971, pp. 6-10.

19. Para Malecki, quien menciona esta escena, «la referencia al término clasista fue una respuesta casi natural, en el sentido que lo que aglutinaba a la mayoría de los militantes de S-S era un sentimiento de clase y no una ideología concreta». Pero queda por dilucidar qué sería ese «sentimiento de clase» cuya naturalidad es sospechada por el propio articulista.

20. En el mismo sentido, Gordillo (2009: 24-26).

21. Por ello es que no puede recalar en una identidad (ni trabajadores ni vecinos, ni peronistas ni socialistas, etc.). El clasismo, tal como trata de ser abordado aquí, es una expresión no identitaria de la política revolucionaria, emancipatoria, de la clase en formación, de una pluralidad que no puede ser reducida a ninguna identidad; y ésta es también una dimensión de su auto-nomía. Lo que no debiera entenderse como ausencia de organización.

22. No pocos activistas de la experiencia clasista comentan, en la actualidad, que la práctica democrática recurrente de las asambleas terminó por cansar a muchos trabajadores; efectivamente, sostener esa subjetivación es una acción que exige, que está siempre en una posición de confrontación y por tanto incómoda respecto de los lugares tradicionales, habituales (es una confrontación permanente de los hábitos, laborales, vecinales, etc.).

\section{RESÚMENES}

El presente trabajo aborda algunos aspectos de las prácticas y elaboraciones políticas que llevaron adelante distintos colectivos de trabajadores en los años sesenta y setenta, con centro en las experiencias cordobesa y de Villa Constitución. El objetivo es interrogarse en torno a la agencialidad de sectores de la clase obrera, al proceso de subjetivación por el cual se configuran como el foco emanador de una política de corte alternativo y emancipatorio. En paralelo, se busca indagar en la elaboración conceptual que los propios trabajadores dieron y dan a su experiencia política de autorganización. La indagación sobre las posibles articulaciones entre lo que se nomina bajo los términos inteligencia y política busca ser, de este modo, una puerta de entrada a las prácticas políticas de clase y a las elaboraciones intelectuales que sobre ellas hicieron los propios protagonistas.

This paper addresses some dimensions of the political practices and thinking carried out by groups of workers during the sixties and seventies in Argentina, focusing in the experiences of Córdoba and Villa Constitución. The aim is to research the agency of the working class, the process of subjectivation out of which workers became the locus of an alternative and emancipatory policy. At the same time, it also investigates the conceptual elaborations that the workers made, and still make, of their own political experience of self-organization. This way of inquiring the links between what is nominated under the terms intelligence and politics looks 
forward to become a gateway to working-class political practices and worker's own intellectual understandings about them.

Cet article abord certains aspects des pratiques et des élaborations politiques qui ont été effectué par divers groupes de travailleurs dans les années 1960 et 1970, principalement dans les expériences cordobesas et à Villa Constitution. L'objectif est d'interroger l'agentialité des secteurs de la classe ouvrière, à propos du processus de subjectivation pour lesquels ils se configurent comme centre émanateur d'une politique alternative et émancipatrice. En parallèle, on cherche à étudier le développement conceptuel que les travailleurs eux-mêmes ont donné et donnent à son expérience politique d'auto-organisation. L'enquête sur les articulations possibles entre ce qui est appelé sous les termes intelligence et politique cherche à être, ainsi, une porte d'entrée dans les pratiques politiques de classe et dans les élaborations intellectuelles que les protagonistes on fait sur leurs pratiques.

\section{ÍNDICE}

Mots-clés: classe ouvrière; démocratie; expérience

Keywords: Working class, Democracy, Experience

Palabras claves: Clase obrera; Democracia; Experiencia

\section{AUTOR}

ROBERTO PITTALUGA

UNLPam/UBA/UNLP

roberto.pittaluga@gmail.com 